\title{
Experimental Study on Mechanical Properties of a Medium Size Box-Type Corrugated Steel Bridge
}

\author{
Wenqiang $\mathrm{FU}^{\mathrm{a}}$, Xinsha $\mathrm{FU}^{\mathrm{a}}$, Yuting $\mathrm{HE}^{\mathrm{a}}$ and Baijian LI ${ }^{\mathrm{a}, 1}$ \\ ${ }^{a}$ School of Civil Engineering and Transportation, South China University of \\ Technology, Guangzhou 510640, China
}

\begin{abstract}
Different from an arch bridge, the load-carrying capacity of a box structure mainly depends on the bending capacity of corrugated steel. This paper explores the mechanical properties of a corrugated steel box bridge. The mechanical properties of a $13 \mathrm{~m}$ span corrugated steel box bridge under static and dynamic loads were tested. Three static load conditions were tested, and four dynamic load conditions were tested, including $20 \mathrm{~km} / \mathrm{h}, 40 \mathrm{~km} / \mathrm{h}, 60 \mathrm{~km} / \mathrm{h}$, and 80 $\mathrm{km} / \mathrm{h}$. Through the analysis of section strain, vault displacement, dynamic strain, and internal force, the following conclusions can be drawn: (1) when the static load changes from the right arch foot and vault to the left arch foot, the strain value of each measuring point continues to increase, which may be caused by the accumulation of deformation due to the adjustment of the stress state of the soil and corrugated steel caused by loading; (2) the displacement change in the test is more sensitive than the strain change; (3) the vault strain reaches the maximum value at a specific speed of $60 \mathrm{~km} / \mathrm{h}$. This is related to the structural resonance caused by vehicle operation, and the natural frequency of the corrugated steel box bridge can be determined by a field vehicle dynamic load test; (4) the damping value of an embedded corrugated steel bridge is large, and the energy dissipation capacity is strong, which is very beneficial to structural earthquake resistance and to reducing the structural resonance under traffic load; (5) the dynamic increasing strain coefficient is less than 1 , which means that the strain caused by a dynamic load is far less than that caused by a static load, and it reaches the maximum value at a certain speed $(60 \mathrm{~km} / \mathrm{h}) ;(6)$ the maximum bending stress and maximum axial stress of the corrugated steel box bridge tested in this paper are basically the same, which indicates that the axial stress of the box structure cannot be ignored. However, the box structure design method proposed in the CHBDC code does not consider the axial stress, so it is necessary to further improve the box structure design method; (7) most of the axial force of a box corrugated steel bridge is tensile force. The pavement structure layer has an effect on the overall performance of the corrugated steel box bridge, which is similar to the decompression plate: it makes the overall stress ( $\sim \mathrm{V}$ section) more uniform and the bending moment smaller.
\end{abstract}

Keywords. Corrugated steel bridge, field tests, box-type, mechanical behavior, internal force analysis

${ }^{1}$ Baijian Li, School of Civil Engineering and Transportation, South China University of Technology, Guangzhou 510640, China; E-mail: BJian_li@163.com. 


\section{Introduction}

A corrugated steel bridge is a flexible arch shell structure, which can adjust the internal force and stress concentration caused by uneven settlement. It is suitable for areas that are cold, have unfavorable geology, or are high fill areas. A corrugated steel bridge has the advantages of fast construction speed and being environmentally friendly. Flexible corrugated steel bridges have been widely used in China's Qinghai, Hunan, Hebei, Inner Mongolia, Guangxi, and other provinces.

In recent years, researchers have conducted in-depth research on corrugated steel structures and obtained positive results. The interaction between the soil and the structure is a key factors that allows corrugated steel to exert load-carrying capacity. Flexible corrugated steel can adjust the distribution of soil pressure, so that the bearing of the soil pressure tends to be uniform in a circumferential direction [1]. In addition, the soil can support the corrugated steel wall to prevent local buckling [2]; under shallow buried conditions, the soil cannot form effective confining pressure on the corrugated steel. The live load has a great influence on the bending moment of the structure, and the bending stress can reach 5 times the yield limit, while the axial stress is only 0.6 times the yield limit [3]. The distribution of soil pressure around the corrugated steel structure depends on the relative stiffness of the structure and the surrounding backfill material. Installing a layer of compressible tire derived aggregate on the corrugated steel structure can effectively reduce the soil pressure around the corrugated steel structure [4]. During the backfilling construction, the ratio of the stress of the arch top to the stress of the arch line decreases with the increase of the backfill height, and the absolute bending moment value decreases with the increase of the backfill height [5]. As vehicles drive over the bridge, the vehicle speed has a great influence on the dynamic response of the structure. The span of the structure, the height of the soil, and the vehicle speed are the main factors that affect the deflection [6]. The dynamic load of vehicles also has an influence on the corrugated steel joint. The strain measured near the joint of a corrugated steel culvert is obviously smaller than the yield strain, and the dynamic deflection is usually $10-40 \%$ less than the static deflection [7]. The damping of a corrugated steel structure is greater than that of a conventional bridge and culvert structure, and the seismic performance is better. However, due to the limited load, the higher the filling height, the greater the stress and displacement, and the smaller the velocity, acceleration, and natural frequency [8]. The bending stress is similar to the circumferential stress, which is contrary to the hoop compressive stress assumption in the current design code. A dynamic load produces more axial force than a static load, but the bending moment is smaller. The asphalt pavement has little influence on the axial force, but it can reduce the bending moment [9]. If the reinforced concrete load-reduction plate is set on the top, the displacement and stress of the corrugated steel vault can be reduced by $53-66 \%$ and $73-82 \%$, respectively, and the bending moment can be effectively reduced by more than $50 \%$ [10-12]. In addition, the combination of a corrugated steel plate and ordinary concrete can significantly improve the rigidity of the components. The combination of a corrugated steel plate and rubber concrete can improve the energy consumption capacity and ductility of the components, and it is more suitable for seismic and seismic structures [13].

However, different from the arch bridge, the load-carrying capacity of the corrugated steel arch bridge mainly depends on the interaction between the soil and the structure. The box structure mainly depends on the bending load-carrying capacity of the corrugated steel itself. The constraint effect of the soil on the box structure is very 
small, and there is almost no beneficial effect [14]. In the CHBDC design code, the limit value of the box structure size is that the span may be no more than $8 \mathrm{~m}$, and the height of the fill may be no more than $1.5 \mathrm{~m}$ [15]. However, with the development of the manufacturing industry, the strength, wave shape, and plate thickness of steel are increasing, and the load-carrying capacity of corrugated steel is increasing. In addition, with the deepening understanding of corrugated steel structures on the part of engineers and researchers, and the emergence of over standard design, researchers have begun to reexamine the applicability of the provisions in the code. Recent studies have carried out scientific research beyond the provisions of the code, hoping to further improve the spanning and bearing capacity of corrugated steel structures. The span of the corrugated steel box bridge in this project is $13 \mathrm{~m}$, which is a box structure beyond the limit of the CHBDC code. Therefore, through field tests, the strain and displacement of a corrugated steel box bridge under three conditions of vehicle static loads, and vehicle speeds of $20 \mathrm{~km} / \mathrm{h}, 40 \mathrm{~km} / \mathrm{h}, 60 \mathrm{~km} / \mathrm{h}$, and $80 \mathrm{~km} / \mathrm{h}$ were tested. The static and dynamic performance of the vault is analyzed and discussed to promote the development of engineering practice and design theory related to the box structure.

\section{Bridge Overview and Test Scheme}

This study considers a single-span corrugated steel box bridge with a span of $13 \mathrm{~m}$ and a rise height of $3.676 \mathrm{~m}$. The bridge is located in the two-way four lane highway of Xining Ring Road in Qinghai Province. The total length of the bridge is $28 \mathrm{~m}$ and the total width is $22 \mathrm{~m}$. The box section consists of three arc sections and two straight sections. The top arc radius is $13 \mathrm{~m}$, the shoulder arc radius is $1.25 \mathrm{~m}$, and the side wall straight section length is $1.358 \mathrm{~m}$. The filling height of the upper part of the vault is $0.72 \mathrm{~m}$. The waveform (super COR) is $400 \times 150 \times 8 \mathrm{~mm}$. The corrugated steel is perpendicular to the road. M20 high-strength bolts of grade 10.9 are used as the connecting bolts of the corrugated steel plate. The ultimate tensile strength and ultimate shear strength of the bolts are $500 \mathrm{MPa}$ and $310 \mathrm{mpa}$, respectively. The corrugated steel plate is connected with the foundation by unequal channel steel; the concrete grade of the foundation is $\mathrm{C} 30$; the height is $2 \mathrm{~m}$; the width of the foundation bottom is $3 \mathrm{~m}$; the load-carrying capacity of the soil foundation under the foundation is not less than $400 \mathrm{kPa}$. A precast concrete block retaining wall is used at the inlet and outlet of the bridge, and a grass planting cone slope is set at the end of the retaining wall. The design water level under the bridge is $1.09 \mathrm{~m}$. To prevent the riverbed from being washed, the bridge is paved with $40 \mathrm{~cm}$ thick C30 concrete. The bolt holes of the corrugated steel joints are sealed with epoxy resin, and the arch back is sprayed with asphalt waterproof. The compactness of backfill soil is not less than $95 \%$.

The test tested the section strain and vault displacement of the corrugated steel box bridge under The test tested the section strain and vault displacement of the corrugated steel box bridge under vehicle load, as well as its distribution along the transverse direction of the bridge. The construction of the bridge was completed at the end of 2019. At the time of the test, the construction of the road was completed, but it was not yet open to traffic. The static and dynamic strain and displacement of the bridge under the action of a ZZ3257N3648B double-bridge 20t dump truck were tested on site. The vehicle specifications are shown in table 1 . 
Table 1. Vehicle indicators.

\begin{tabular}{lclllllll}
\hline Vehicle model & weight & $\begin{array}{l}\text { Front } \\
\text { axle } \\
\text { weight }\end{array}$ & $\begin{array}{l}\text { Rear } \\
\text { biaxial } \\
\text { weight }\end{array}$ & $\begin{array}{l}\text { Vehicle } \\
\text { width }\end{array}$ & $\begin{array}{l}\text { Vehicle } \\
\text { length }\end{array}$ & Wheelbase & $\begin{array}{l}\text { Rear } \\
\text { track }\end{array}$ & $\begin{array}{l}\text { Front } \\
\text { track }\end{array}$ \\
\hline ZZ3257N3648B & $121.1 \mathrm{kN}$ & $47.1 \mathrm{kN}$ & $74 \mathrm{kN}$ & $2.496 \mathrm{~m}$ & $8.214 \mathrm{~m}$ & $3.625+1.35 \mathrm{~m}$ & $1.83 \mathrm{~m}$ & $2.022 \mathrm{~m}$ \\
\hline
\end{tabular}

Five measuring points were set in the span direction of the bridge (the corresponding strain gauge numbers are respectively: left arch haunch $1 \sim 20$, left arch shoulder 21 40, vault 41 60, right arch shoulder 61 80, and right arch haunch $81 \sim 100)$. Five test sections $\mathrm{I} \sim \mathrm{V}$ were set horizontally for the bridge. The longitudinal and transverse strains of wave peaks and valleys were tested at each measuring point, with a total of 100 strain gauges. A total of 5 displacement meters were placed at the vault positions (numbered $\mathrm{A} \sim \mathrm{E}$ ). The odd-numbered strain gauges were transverse strain gauges, and the even-numbered strain gauges were longitudinal strain gauges. The longitudinal strain gauges of the wave crest, which was close to the side of the soil, were $[2,6,10,14,18],[22,26,30,34,38]$, [42, 46, 50, 54, 58], [62, 66, 70, 74, 78], $[82,86,90,94,98]$. The remaining even numbered strain gauges are trough longitudinal strain gauges, which were close to the inner side of the bridge. The number of transverse strain gauges was the same as the above rule. The overview of the bridge and the test scheme are shown in figure 1.

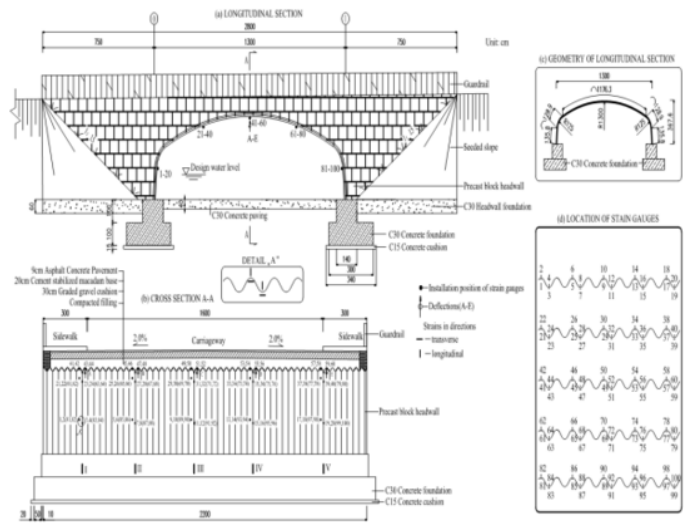

Figure 1. General situation and test scheme of corrugated steel bridge.

The model of the steel strain gauge is: BE120-3AA-P300, the length is $3 \mathrm{~mm}$, the resistance value is $120 \Omega \pm 0.3 \%$, and the sensitivity coefficient of the strain gauge is $2.11 \pm 1 \%$. The displacement sensor model is a $5 \mathrm{G} 105$ resistive linear displacement sensor, the range is $100 \mathrm{~mm}$, the linear accuracy $(\% \mathrm{FS}) \leq 0.25 \%$, the repeatability accuracy is $0.01 \mathrm{~mm}$, the sensitivity coefficient is $1.98 \pm 2 \%$, and the shape size is $185 \times 14.8 \times 25 \mathrm{~mm}$. The data acquisition system is a DH3816N static strain gauge, which is a fully intelligent data acquisition system with 72 channels. It is suitable for the model and other tests with relatively concentrated measuring points, and it realizes the measurement of the corresponding strain stress, force, displacement, and other physical quantities. The strain gauge is connected with a static strain instrument by a $1 / 4$ bridge. To prevent the influence of temperature change, a temperature compensation piece is also set. The displacement sensor is connected with the strain gauge by a half bridge without temperature compensation. 
The static strain and displacement under vehicle load, and the dynamic strain of two measuring points on the vault during driving, were tested. The vehicle load acted on one side of the carriageway. The outer side of the wheel was $1 \mathrm{~m}$ away from the hard shoulder (see figure 2). The three load cases of the static load test were: (1) double rear wheels acted on the arch foot; (2) double rear wheels acted on the vault; and (2) double rear wheels acted on the other side of the arch foot. The loading time of the static load test was $20 \mathrm{~min} /$ point (as shown in the static strain distribution diagram in figure 3 for the three load conditions). The vehicle trajectory in the dynamic load test was the same as for the static load test, and the outer side of the wheel was kept $1 \mathrm{~m}$ away from the hard shoulder. The dynamic strains of $41 \sim 48$ strain gauges at the four speeds were tested : (1) $20 \mathrm{~km} / \mathrm{h}$, (2) $40 \mathrm{~km} / \mathrm{h}$, (3) $60 \mathrm{~km} / \mathrm{h}$ and (4) $80 \mathrm{~km} / \mathrm{h}$.

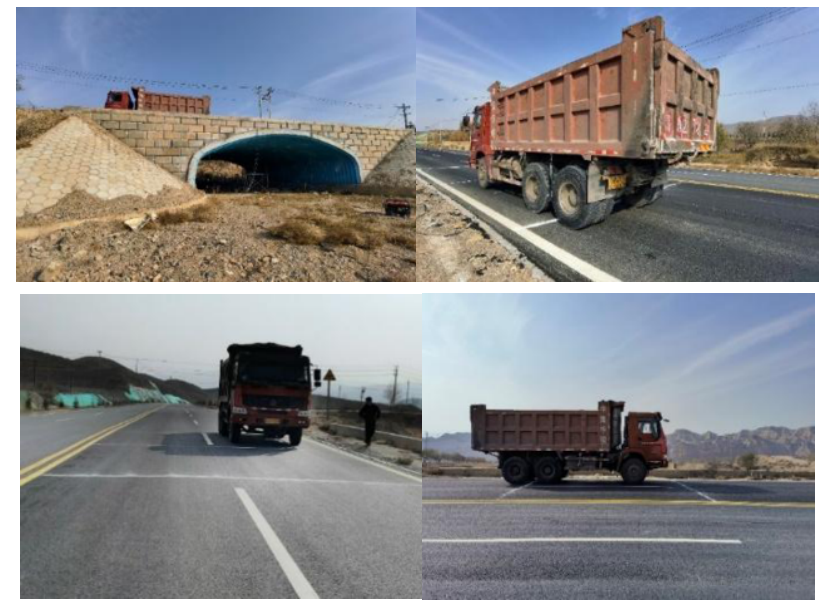

Figure 2. Vehicle loading for field test.

\section{Result Analysis and Discussion}

\subsection{Static Test Results}

\subsubsection{Test Error}

The test results of the resistance strain gauge and displacement meter were greatly affected by the field environment (rain and snow, test voltage, surrounding vibrations). Considering the instrument installation, structural dimension deviation, and human factors, we expect some errors in the tests, which should be considered in the analysis of the results.

The theoretical error of the resistance displacement sensor can be calculated by the following formula:

$$
\delta_{f}=\sqrt{\delta_{1}^{2}+\delta_{2}^{2}+\delta_{3}^{2}+\delta_{4}^{2}}=\sqrt{0.02^{2}+0.01^{2}+0.025^{2}+0.005^{2}}= \pm 3.39 \%
$$

In the formula, $\delta 1=2.0 \%$-displacement converter error; $\delta 2=1.0 \%$-compensation error; $\delta 3=2.5 \%$-measurement amplifier error; and $\delta 4=2.0 \%$-calibration error. 
The theoretical error of the strain gauge is:

$$
\delta_{\varepsilon}=\sqrt{\delta_{5}^{2}+\delta_{6}^{2}+\delta_{7}^{2}+\delta_{8}^{2}}=\sqrt{0.02^{2}+0.01^{2}+0.025^{2}+0.02^{2}}= \pm 3.91 \%
$$

In the formula, $\delta 5=2.0 \%$-strain gauge error; $\delta 6=1.0 \%$-compensation error; $\delta 7=2.5 \%$-measurement amplifier error; $\delta 8=2.0 \%$ - Error caused by assuming steel elastic modulus $\mathrm{E}_{\mathrm{s}}=2.06 \times 10^{11}$.

\subsubsection{Strain and Displacement}

The static strain and vertical displacement of vault under vehicle load are shown in figure 3. It can be seen from figure 3 that under working condition I, the double rear axle of the vehicle acts on the right arch and the front axle acts on the vicinity of the right arch. At this time, the maximum strain $65,143,-110,-130$ is generated at the right spandrel (The strain gauges are numbered: 62, 66, 64, 68), followed by the strain value near the right arch foot. In the transverse distribution of strain along the bridge, the maximum strain occurs in Section II, and decreases in order to both sides. The values of I and V sections are the smallest because they are close to the end wall. The vault has a downward displacement on the half of the road surface where the vehicle acts, the II section has the largest vertical displacement $(-0.28 \mathrm{~mm})$, the I and III sections are slightly smaller, and the IV section has an upward displacement. It may be caused by the poor working condition of the displacement meter or the upward warping of the pavement structural layer plate, and the specific situation can not be determined for the time being. The magnitude of the displacement value is similar to the strain distribution law.

Under working condition II, the dual rear axle acts on the vault, and the front axle acts near the left spandrel. The maximum strains of 88, 173, -106, and -113 (strain gauge numbers: $62,66,64$, and 68) are generated at the right spandrel in the same way as in condition I. The structure cannot recover the deformation without loading, which is likely due to the accumulation of a deformation caused by a loading interval that is too short. Different from working condition I, the strain value of the vault is larger than that of working condition I. The dual rear axles act on the vault directly, so the strain of the vault will increase significantly. The strain value of the left arch foot (strain gauge No. $1 \sim 20$ ) corresponding to the front axle is ranked third. The strain distribution along the transverse direction of the bridge reveals that section II has the largest strain, and it decreases to both sides. Sections I and V are close to the end wall, so their values are the smallest. The distribution of the vault displacement is similar to that of work condition I, but the vault displacement of work condition II is the same $(-0.71 \mathrm{~mm})$, and this is larger than condition I and condition III.

Under condition III, the vehicle starts to leave the corrugated steel bridge, and the double rear axle acts on the left arch foot and front axle. At this time, the strain values of the vault, the spandrel, and the side arch foot increase significantly. Similarly, due to the accumulation of deformation, the strain value of the spandrel in condition I does not decrease because of the departure of the vehicle. On the contrary, when the vehicle changes from condition I to condition III, the strain value of the loading point increases in turn. The displacement of the vault is smaller than that of conditions I and II, which indicates that the displacement change is more sensitive than the strain change. 


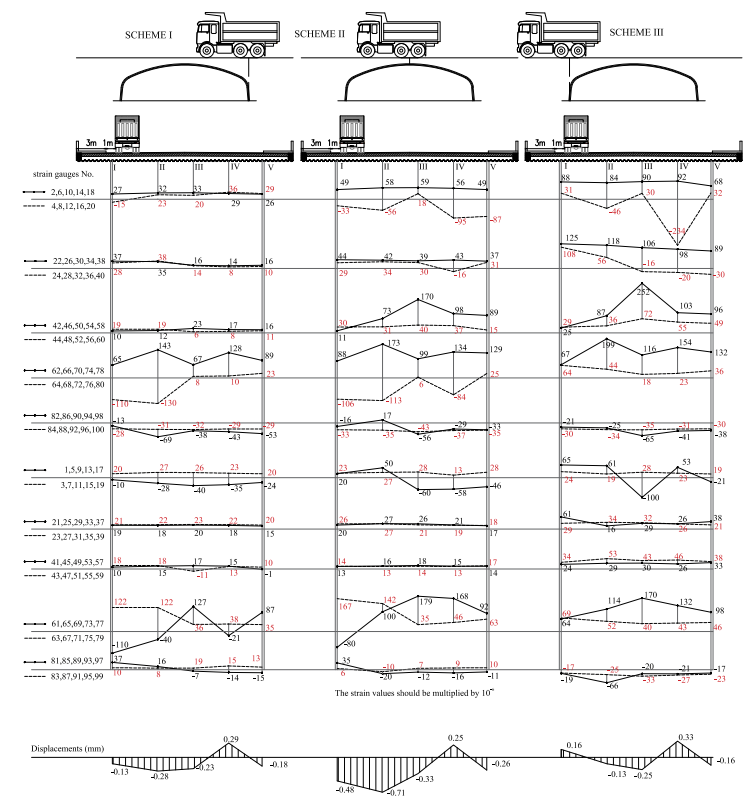

Figure 3. Static strain and vertical displacement of the vault under vehicle load.

\subsection{Dynamic Test Results}

\subsubsection{Dynamic Strain}

Figure 4 shows the dynamic strain of the vault under four vehicle speeds of 20, 40, 60 and $80 \mathrm{~km} / \mathrm{h}$ (strain gauge numbers $41 \sim 48$ ). It can be seen from the figure that the dynamic strain of each measuring point has two peaks, which is caused by the front axle and dual rear axle passing through the vault respectively. The first peak is caused by the front axle and the second peak is caused by the dual rear axle. Moreover, the faster the vehicle speed is, the narrower the distribution of dynamic strain on the time axis is. With the increase of vehicle speed, the time interval between the two peaks is shorter.
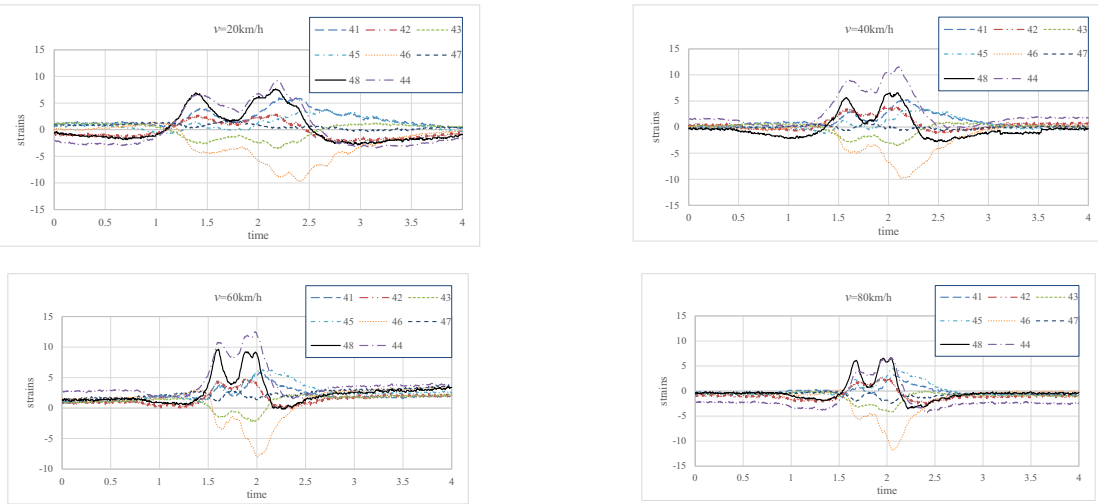

Figure 4. Dynamic strain of vault under vehicle dynamic load $\left(10^{-6}\right)$. 
Combining figure 4 and table 2, it can be seen that the vault strain does not always increase with the increase in the vehicle speed; rather, it reaches the maximum value at a specific vehicle speed. In this test, the specific speed is $60 \mathrm{~km} / \mathrm{h}$, which should be related to the structural resonance caused by vehicle operation. When the vehicle is running, the frequency of the concentrated load caused by the wheel passing through a certain point can be calculated by the track width/speed. For example, the distance between the front wheel and the middle rear wheel is $3.625 \mathrm{~m}$, the distance between the two rear wheels is $1.35 \mathrm{~m}$, and the vehicle speed is $60 \mathrm{~km} / \mathrm{h}$. The frequency of action between the front wheel and the middle rear wheel is $\mathrm{fl}=60 \mathrm{~km} / \mathrm{h} / 3.625 \mathrm{~m}=4.6 \mathrm{~Hz}$, and the action frequency of the double rear wheels is $\mathrm{f} 2=60 \mathrm{~km} / \mathrm{h} / 1.35 \mathrm{~m}=12.38 \mathrm{~Hz}$. Therefore, according to the dynamic strain distribution diagram, the first natural frequency of the corrugated steel bridge is estimated to be about $4.6 \mathrm{~Hz}$, and the second natural frequency is estimated to be about $12.38 \mathrm{~Hz}$.

Table 2. Dynamic and static strain of vault.

\begin{tabular}{lllllllll}
\hline Speed & 41 & 42 & 43 & 44 & 45 & 46 & 47 & 48 \\
\hline $\begin{array}{l}\text { Static } \\
\text { load }\end{array}$ & 24 & 25 & 34 & 30 & 29 & 87 & 53 & 36 \\
20 & 5.99 & 3.07 & -3.53 & 10.45 & 3.82 & -9.81 & 1.69 & 7.65 \\
40 & 5.22 & 3.99 & -3.53 & 13.22 & 3.52 & -9.81 & -0.77 & 6.58 \\
60 & 5.83 & 4.75 & -2.3 & 14.3 & 6.27 & -7.97 & 3.68 & 9.64 \\
80 & 3.22 & -2.76 & -4.14 & 8.46 & 4.59 & -11.8 & -2.45 & 6.58 \\
\hline
\end{tabular}

\subsubsection{Damping Ratio}

The time domain damping ratio can be calculated based on the strain, and the calculation formula is:

$$
\Delta=\frac{1}{2 k \pi} \ln \frac{\varepsilon_{n p}-\varepsilon_{n v}}{\varepsilon_{n k p}-\varepsilon_{n k v}}
$$

In the formula: $\Delta$-time-domain damping ratio; k-specified number of cycles; $\varepsilon_{n p}$-the peak value of the nth strain waveform; $\varepsilon_{n v}-$ the trough value of the nth strain waveform; $\varepsilon_{n k p}$-the peak value of the $n+k$ th strain waveform ; $\varepsilon_{n k v}$-the trough value of the $n+k$ th strain waveform.

The damping calculated according to the strain is related to the position of the measuring points, and each measuring point corresponds to a damping value. The damping distribution is shown in figure 5 . When the vehicle speed is $20 \mathrm{~km} / \mathrm{h}$, the damping ratio varies from $1.29 \%$ to $22.43 \%$. When the vehicle speed is $40 \mathrm{~km} / \mathrm{h}$, the damping ratio varies from $2.29 \%$ to $19.37 \%$. When the vehicle speed is $60 \mathrm{~km} / \mathrm{h}$, the damping ratio varies from $1.06 \% \sim 21.81 \%$. When the vehicle speed is $80 \mathrm{~km} / \mathrm{h}$, the damping ratio varies from $2.52 \%$ to $25.29 \%$. The average damping ratio is $12.37 \%$. The damping change is not significantly related to the vehicle speed. The calculated damping of the wheel pressure range is slightly larger than that of other points. From the damping distribution range, it can be seen that the damping value of the embedded steel corrugated plate bridge is larger than that of other types of bridges (such as a beam bridge and a box girder bridge), and the energy consumption capacity is strong. 


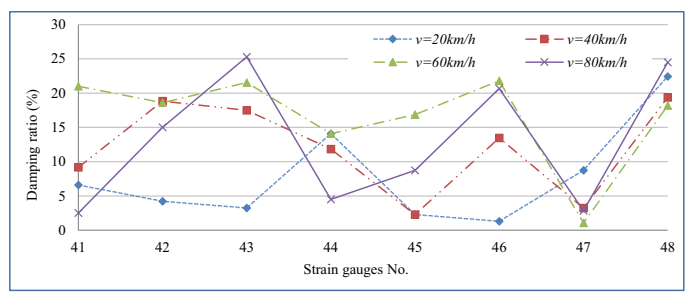

Figure 5. Damping ratio.

\subsubsection{Natural Frequency}

The natural frequency of the structure can be directly generated during the calculation of the damping ratio. It is the calculation result attached to the calculation of the damping ratio. The calculation formula is:

$$
f=\frac{k}{T_{n k p}-T_{n p}}
$$

In the formula: $f$ - the natural frequency of the measuring point; $k$ - the specified number of cycles; $T_{n p}$ - the time corresponding to the crest of the nth strain waveform; $T_{n k p}$ - the time corresponding to the crest of the $\mathrm{n}+\mathrm{k}$ strain waveform.

Since the dynamic strain waveform of each measuring point is different, the calculated natural frequency is related to the measuring point position, as shown in figure 6 . When the vehicle speed is $20 \mathrm{~km} / \mathrm{h}$, the natural frequency change range is $3.11 \sim 9.41 \mathrm{~Hz}$. When the vehicle speed is $40 \mathrm{~km} / \mathrm{h}$, the natural frequency change range is $4.97 \sim 10.13 \mathrm{~Hz}$. When the vehicle speed is $60 \mathrm{~km} / \mathrm{h}$, the natural frequency range is 2.14 $\sim 12.70 \mathrm{hz}$. When the vehicle speed is $80 \mathrm{~km} / \mathrm{h}$, the natural frequency range is $5.03 \sim$ 18.18hz. The average value is: $7.45 \mathrm{~Hz}$ at $20 \mathrm{~km} / \mathrm{h}, 7.62 \mathrm{~Hz}$ at $40 \mathrm{~km} / \mathrm{h}, 4.71 \mathrm{~Hz}$ at $60 \mathrm{~km} / \mathrm{h}, 9.10 \mathrm{~Hz}$ at $80 \mathrm{~km} / \mathrm{h}$. According to the natural frequencies of different vehicle speeds, it can be predicted that the dynamic augmentation coefficient of the structure will reach the extreme value when the vehicle speed reaches $60 \mathrm{~km} / \mathrm{h}$. This is because the frequency generated by vehicle operation is $\mathrm{F} 1=4.6 \mathrm{hz}$, and the natural frequency of the structure is $4.71 \mathrm{hz}$. The two frequencies are close, and the corrugated steel will produce resonance.

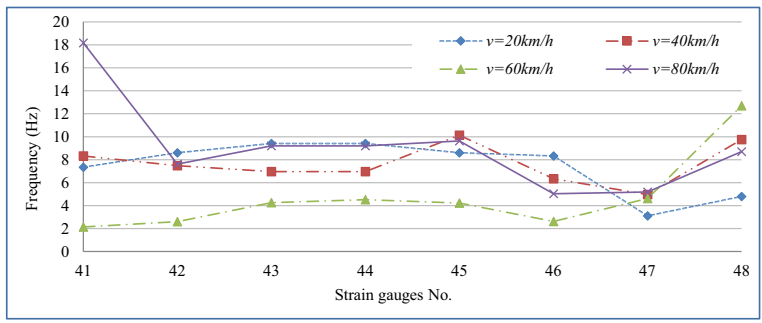

Figure 6. Natural frequency. 


\section{Strain Dynamic Increase Factor DAFs}

Figure 7 shows the dynamic strain increase coefficient of the $41 \sim 48$ measuring points. Because of the different dynamic strain at different measuring points, the calculated dynamic increase coefficient is related to the location of the measuring point. The maximum value occurs at the No. 44 strain gauge, followed by the No. 48 Strain gauge; these two strain gauges are the trough strains near the point of the application of wheel pressure. When the vehicle speed is $20 \mathrm{~km} / \mathrm{h}$, the variation range of the strain dynamic increase coefficient is $0.03 \sim 0.35$. When the vehicle speed is $40 \mathrm{~km} / \mathrm{h}$, the variation range of the strain dynamic increase coefficient is $0.01 \sim 0.44$. When the vehicle speed is $60 \mathrm{~km} / \mathrm{h}$, the change range of the increase coefficient is $0.07 \sim 0.48$. When the vehicle speed is $80 \mathrm{~km} / \mathrm{h}$, the change range of the strain dynamic increase coefficient is $0.05 \sim 0.28$. The average value is 0.16 at $20 \mathrm{~km} / \mathrm{h}, 0.17$ at $40 \mathrm{~km} / \mathrm{h}, 0.20$ at $60 \mathrm{~km} / \mathrm{h}$, and 0.15 at $80 \mathrm{~km} / \mathrm{h}$. This shows that the dynamic increasing coefficient of strain is less than 1; that is, the strain caused by the dynamic load is far less than that caused by static load, and it reaches the maximum value $(60 \mathrm{~km} / \mathrm{h})$ at a certain speed, which indirectly shows the accuracy of the previous prediction.

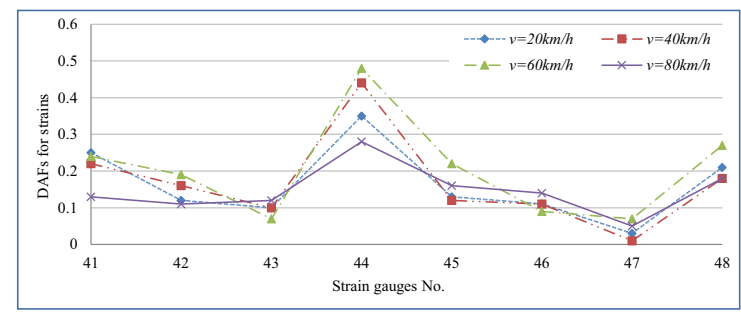

Figure 7. Strain dynamic increase coefficient

\subsection{Internal Force Analysis}

The corrugated steel structure that interacts with the soil and the structure is usually in the state of a combination of compression and bending. There are not only axial stress but also bending stress on the cross section of corrugated steel. However, only the bending design of corrugated steel box structure is stipulated in the design code, and whether the section bears axial force is not considered. That is to say, the clause in the design code thinks that the corrugated steel box structure only bears bending moment or the bending moment plays a controlling role, and the axial force can be ignored. In order to ascertain the stress state, the numerical values of axial force and bending moment are calculated by formula (3), and the distribution state of these two kinds of internal forces and their influence on corrugated steel box bridge are distinguished. Formula (3) is applicable to the elastic stage of corrugated steel, that is to say, the measured strain value should be less than 0.001 , otherwise the steel enters the plastic stage, and formula (3) cannot be used to calculate the axial force and bending moment.

$$
\left\{\begin{array}{l}
N=\frac{\varepsilon_{1}+\varepsilon_{2}}{2} E A \\
M=\frac{\left(\varepsilon_{1}-\varepsilon_{2}\right) E I}{2 d}
\end{array}\right.
$$


In the formula: $\varepsilon 1=$ corrugated plate wave peak strain; $\varepsilon 2=$ corrugated plate trough strain; $\mathrm{E}=$ steel elastic modulus; $\mathrm{A}=$ corrugated steel plate unit width cross-sectional area; $I=$ corrugated steel plate unit width bending moment of inertia; $d=$ the wave height of corrugated steel plate; $\mathrm{N}=$ axial force; and $\mathrm{M}=$ bending moment.

The internal force of the corrugated steel section under vehicle load is shown in figure 8. Under working condition I, the dual rear axle acts on the arch foot, and the front axle acts near the spandrel. At this time, the arch foot on the load side is compressed, and the spandrel bends downward; the vault, spandrel, and arch foot on the non-load side are pulled. Sections I and II are under wheel compression. Section I is close to the end wall and is greatly affected by the end wall constraint, while Section II is weakly affected by the end wall constraint. Therefore, the pressure $(-107.71 \mathrm{kN}$ to $44.16 \mathrm{kN})$ and bending moment $(-10.59 \mathrm{kN} \cdot \mathrm{m}$ to $-6.79 \mathrm{kN} \cdot \mathrm{m})$ of section II are larger than that of section I.

The internal force distribution of Working Condition II and Working Condition III is the same as that of case I. The difference is that in the process of a vehicle moving, the axial force of the measuring point under the wheel pressure becomes larger and larger, and it is tensile; this is probably caused by the accumulation of deformation. In addition, a composite structure is formed among the pavement structure layer, backfill, and corrugated steel box arch. There is friction between different material layers, and the corrugated steel in the lower part is in tension under the action of the vertical load. The maximum bending moment of sections I and II occurs under condition II, the maximum bending moment of section III occurs under condition I, the maximum bending moment of Section IV occurs under condition III, and the maximum axial force occurs under condition III. The maximum axial force and bending moment values under the three working conditions are $348.97 \mathrm{kN}$ and $12.64 \mathrm{kN} \cdot \mathrm{m}$, respectively.

The internal force calculation of the box structure is specified in the CHBDC. Although the CHBDC method is applicable to the box structure with a span of $8 \mathrm{~m}$ and a filling height of less than $1.5 \mathrm{~m}$, it still plays an effective guiding role in the design of the box structure. Therefore, the CHBDC method is used to check the internal force of the box structure of this project, and it is compared with the test value. The bending moment is calculated as follows:

$$
\left\{\begin{array}{l}
M_{c L}=\kappa C_{1} k_{3} L_{L} D_{h} \\
M_{h L}=(1-\kappa) k_{R} C_{1} k_{3} L_{L} D_{h}
\end{array}\right.
$$

In the formula: $\kappa=0.70-0.0328 \mathrm{Dh}$, dome bending moment coefficient; $\mathrm{C} 1=1.0$ (single axis), $\mathrm{C}_{1}=0.5+\mathrm{D}_{\mathrm{h}} / 15.24 \leq 1.0$ (multi-axis); $\mathrm{k}_{3}=\left[0.08-0.002\left(3.28 \mathrm{D}_{\mathrm{h}}-20\right)\right] /\left(\mathrm{H} / \mathrm{D}_{\mathrm{h}}\right)^{0.2}$; $\mathrm{L}_{\mathrm{L}}=\mathrm{A}_{\mathrm{L}} / \mathrm{k}_{4}$; Dh-structural span, $\mathrm{m} ; \mathrm{M}_{\mathrm{cL}}$-arch bending moment generated by live load, $\mathrm{kN} \cdot \mathrm{m} / \mathrm{m} ; \mathrm{M}_{\mathrm{hL}}$-spandrel bending moment generated by live load, $\mathrm{kN} \cdot \mathrm{m} / \mathrm{m} ; \mathrm{k}_{\mathrm{R}}$ $=0.452 \mathrm{H}+0.48 \leq 1.0$, the spandrel bending moment reduction factor of the box structure; when $\mathrm{D}_{\mathrm{h}}<3.6 \mathrm{~m}, \mathrm{~A}_{\mathrm{L}}$-single axle load, $\mathrm{D}_{\mathrm{h}}>3.6 \mathrm{~m}, \mathrm{~A}_{\mathrm{L}}$ - adjacent two Total axle load; $\mathrm{k}_{4}$ calculate the coefficient of live load bending moment; $\mathrm{L}_{\mathrm{L}}$-live load equivalent line load, $\mathrm{kN} / \mathrm{m}$; H-fill thickness, $\mathrm{m}$. 


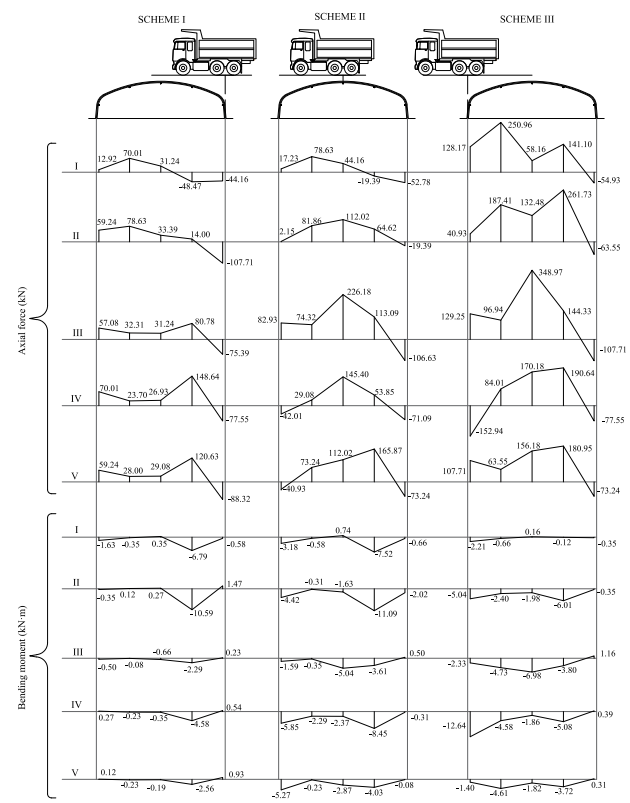

Figure 8. Internal force of corrugated steel box bridge section.

$$
\begin{aligned}
& M_{c L}=0.2736 \times 1.0 \times 0.062 \times 133.2 \times 13=29.37 \mathrm{kN} \cdot \mathrm{m} \\
& M_{h L}=(1-0.2736) \times 0.81 \times 1.0 \times 0.062 \times 133.2 \times 13=63.17 \mathrm{kN} \cdot \mathrm{m}
\end{aligned}
$$

In the test, the maximum bending moment of the vault is $-6.98 \mathrm{kN} \cdot \mathrm{m}$, and the maximum bending moment of the spandrel is $-12.64 \mathrm{kN} \cdot \mathrm{m}$. Obviously, the calculated bending moment of CHBDC is conservative, but it ignores the influence of axial force. The test proves that the corrugated steel box bridge also has relatively large axial force. The axial stress is $34.02 \mathrm{MPa}$ and the bending stress is $34.23 \mathrm{MPa}$, which are almost equivalent. Therefore, the influence of axial force on corrugated steel box bridge cannot be ignored. However, the comparison between the calculated results and the test results of the above-mentioned CHBDC box bridges is only effective for this project, and more test data is needed to prove the applicability of the design method of CHBDC box type bridges to other box bridges.

\section{Discussion}

Given the test results of this experiment, there are several points worthy of attention. (1) The strain and internal force of the measuring point does not mean that if the load is applied to a certain point, the value of this point will be the maximum. However, the values of all of the measuring points will continue to increase with the movement of the vehicle load, and this is the result of the accumulation of deformation. This may be due to the influence of the arch backfill; that is, when the load is applied to the structure, the flexible corrugated steel deforms and adjusts the distribution of the earth pressure. This state may last for a long time. When the vehicle moves to the next working 
condition, the structural deformation under the previous working condition does not resume the initial state. Rather, it maintains the deformation state under the last working condition, so the load is applied at the next working condition. This shows that the strain and internal force of conditions I, II, and III increase continuously. (2) Most of the axial force of the box corrugated steel bridge is tension rather than pressure, which is probably due to the superposition structure formed by the box corrugated steel, backfill, and pavement structure layer. There is friction between the different material layers, and the friction force will cause stress redistribution between the layers of composite materials. That is: under the vertical load, the upper layer of pavement structure experiences compression, and the lower layer of corrugated steel experiences tension. Not all of the material interface is smooth, and the corrugated steel bears the load alone. (3) The pavement structure layer may have an impact on the overall performance of the corrugated steel box bridge, and it play a similar role as a pressure reducing plate. This makes the overall force ( $\mathrm{I} \sim \mathrm{V}$ sections) more uniform, and the strain of the measuring point under the wheel pressure is not much greater than that of the other measuring points. This rule can also be found from the internal force distribution of the $\mathrm{I} \sim \mathrm{V}$ sections. The bending stiffness of the pavement structure layer is much greater than that of the soil, so it can effectively reduce the bending moment of the structure. Because the flexural stiffness of the pavement structure layer is much greater than that of soil, the bending moment of the structure can be reduced effectively.

\section{Research Limitations and Recommendations}

This paper introduces the field test of a corrugated steel box bridge with a span of $13 \mathrm{~m}$. The strain, vertical displacement and internal force of the vault are analyzed. In addition, the dynamic performance of the structure at four speeds was tested. The research results of this paper are only valid for this experiment. Only one test vehicle was used this time, and the structural strain and displacement under the anti-symmetric arrangement of multi-vehicle parallel and two-way vehicles were not tested. The general situation and summary of mechanical properties under other loading conditions cannot be carried out. In addition, the numerical analysis method is not used to further summarize the mechanical properties of the bridge. This is the limitation of this paper. In the future, the main influence parameters and static/dynamic characteristics of the structure will be further studied by numerical analysis, and it is hoped that a simple and reasonable structural analysis method can be obtained.

\section{Conclusions}

In this paper, the mechanical properties of a corrugated steel box bridge are explored. The mechanical properties of a 13m-span corrugated steel box bridge under static and dynamic loads were tested on site. Three kinds of working conditions were tested under a static load, and four kinds of speed were tested under a dynamic load, including at speeds of $20 \mathrm{~km} / \mathrm{h}, 40 \mathrm{~km} / \mathrm{h}, 60 \mathrm{~km} / \mathrm{h}$, and $80 \mathrm{~km} / \mathrm{h}$. Through the analysis of section strain, vault displacement, dynamic strain, and internal force, the following conclusions can be obtained:

1. When the static load changes from the right arch foot and vault to the left arch foot, the strain value of each measuring point increases continuously, but it does not 
increase or decrease with the loading and unloading. This may be due to the fact that the soil and corrugated steel can adjust the stress state under loading, resulting in the accumulation of deformation. The displacement change in the test is more sensitive than the strain change.

2. The vault strain does not always increase with the increase of vehicle speed, but it reaches the maximum at a certain speed. In this test, the vehicle speed is $60 \mathrm{~km} / \mathrm{h}$, which is related to the structural resonance caused by vehicle operation. The frequency of vehicle running is $4.6 \mathrm{hz}$, and the natural frequency of the structure is $4.71 \mathrm{hz}$; these values are similar. Therefore, the natural vibration frequency of a corrugated steel box bridge can be determined by an on-site vehicle dynamic load test.

3. The damping value of the embedded steel corrugated plate bridge is larger than that of other types of bridges (such as beam and box girder bridges), and the energy dissipation capacity is stronger, which is very beneficial to $t$ structural seismic resistance and to reducing the structural resonance under traffic load.

4. The strain dynamic increase factor tested in this test was less than 1; that is, the strain caused by the dynamic load was far less than the strain caused by the static load, and it reached the maximum value $(60 \mathrm{~km} / \mathrm{h})$ at a certain vehicle speed.

5 . The maximum bending stress of the corrugated steel box bridge tested in this test is basically the same as the maximum axial stress, which indicates that the axial stress of the box structure cannot be ignored. However, the box structure design method proposed in the CHBDC code does not consider the axial stress, so it is necessary to further improve the box structure design method.

6. Most of the axial force of the corrugated steel box bridge is tensile force. The pavement structure layer has an impact on the overall performance of the corrugated steel box bridge, which is similar to the effect of the pressure reducing plate: it makes the overall stress $(\mathrm{I} \sim \mathrm{V}$ sections) more uniform and the bending moment smaller.

\section{Acknowledgements}

This work was supported by the National Natural Science Fund under Grant (number 51278202). The authors are grateful to Zhengping Road and Bridge Construction Co., Ltd, and Qinghai Lutuo Engineering Facilities Manufacturing Co., Ltd for providing test site. The authors would also like to thank Youhong Peng for supporting this research.

\section{Notation List}

$\delta_{1}=2.0 \%$ - Displacement converter error;

$\delta_{2}=1.0 \%$ - Compensation error;

$\delta_{3}=2.5 \%$ - Measuring amplifier error;

$\delta_{4}=2.0 \%$ - Calibration error;

$\delta_{5}=2.0 \%$ - Strain gauge error;

$\delta_{6}=1.0 \%$ - Compensation error;

$\delta_{7}=2.5 \%$ - Measuring amplifier error;

$\delta_{8}=2.0 \%$ - Assuming the error caused by the elastic modulus of steel Es $=2.06 \times 10^{11}$;

$\Delta$ - Time domain damping ratio;

$k$ - Specified number of cycles; 
$\varepsilon_{n p}$-Peak value of the nth strain waveform;

$\varepsilon_{n v}$-The trough value of the nth strain waveform;

$\varepsilon_{n k p}$-The peak value of the $\mathrm{n}+\mathrm{k}$ strain waveform;

$\varepsilon_{n k v}$-The trough value of the $\mathrm{n}+\mathrm{k}$ th strain waveform;

$f$ - Natural frequency of measuring point;

$T_{n p}$-The time corresponding to the peak of the nth strain waveform;

$T_{n k p}$-The time corresponding to the peak of the $\mathrm{n}+\mathrm{k}$ strain waveform;

$\varepsilon_{1}$ - Corrugated board wave strain;

$\varepsilon_{2}$ - Corrugated board trough strain;

$E$-Steel modulus of elasticity;

$A$ - Cross-sectional area per unit width of corrugated steel sheet;

$I$ - Bending moment of inertia per unit width of corrugated steel plate;

$d$-Wave height of corrugated steel plate;

$N$-Axial force;

$M$-Bending moment.

\section{References}

[1] Watkins RK, Moser RP. The structural performance of buried corrugated steel pipes. Logan: Engineering Experimentation Station, Utah State University; 1969. p. 112.

[2] Chen TL, Su MZ, Pan CL, Zhang L, Wang HM. Local buckling of corrugated steel plates in buried structures. Thin-Walled Structures. 2019 Nov; 144: 106348.

[3] Kearns O, Moore ID, Hoult NA. Measured Responses of a corrugated steel ellipse culvert at different cover depths. Journal of Bridge Engineering. 2020 Nov; 25(11): 04020096.

[4] Mahgoub A, Naggar HE. Innovative application of tire-derived aggregate around corrugated steel plate culverts. Journal of Pipeline Systems Engineering and Practice. 2020 Aug; 11(3): 04020025.

[5] Liu BD, Sun HB, Xu WB, et al. Research on the law of stress development along backfilling process between crest and valley of buried corrugated steel pipe culverts. International Journal of Steel Structures. 2021 Feb; 21(1): 142-153.

[6] Li Baijian, Fu Xinsha, Zhu Liangsheng.. Contrastive Research on Dynamic Analysis Methods of CSP Structure Based on Vehicle-bridge Interaction. Highway Engineering. 2019 Dec; 44(06): 1-8+32.

[7] Sheldon T, Sezen H, Moore ID. Joint response of existing pipe culverts under surface live loads. Journal of Performance of Constructed Facilities. 2015 Feb; 29(1): 04014037.

[8] Maleska T, Beben D. Behaviour of corrugated steel plate bridge with high soil cover under seismic excitation. In: Beben D, Rak A, Perkowski Z, editors. 3rd Scientific Conference Environmental Challenges in Civil Engineering; 2018 Apr 23-25; Opole, Poland. Les Ulis(Essonne): EDP Sciences; 174. 04003 .

[9] Liu YC, Hoult NA, Moore ID. Structural performance of in-service corrugated steel culvert under vehicle loading. Journal of Bridge Engineering. 2020 Mar; 25(3): 04019142.

[10] Beben D, Stryczek A. Numerical analysis of corrugated steel plate bridge with reinforced concrete relieving slab. Journal of Civil Engineering and Management. 2016 Jul; 22(5): 585-596.

[11] Li Baijian, Fu Xinsha, Zhu Liangsheng. Research on Mechanical Properties of Corrugated Steel Plate with Relieving Slab Based on Equivalent Stiffness. Journal of South China University of Technology (Natural Science Edition). 2018 Sept; 46(09): 131-139.

[12] Maleska T, Beben D. Numerical analysis of a soil-steel bridge during backfilling using various shell models. Engineering Structures. 2019 Oct; 196: 109358.

[13] Liu BD, Zhang ZN, Zhang MQ, Wang XX. Experimental study of the mechanical performance of corrugated steel plate-concrete composite structures. International Journal of Steel Structures. 2019 Jun; 19(3): 733-746.

[14] Corrugated Steel Pipe Institute, American Iron and Steel Institute, editors. Handbook of Steel Drainage \& Highway Construction Products. 2nd Canadian ed. Cambridge, Canada: The Institute; 2007. p. 470.

[15] Canadian Standards Association, editors. Canadian Highway Bridge Design Code, CAN/CSA-S6-06. 3rd ed. Mississauga, Ontario: Canadian Standards Association; 2006. p. 608. 